\title{
Argument Quality and Review Adoption: Interaction Effect of Product and Review Type
}

\section{Jiali Liu}

Kolon China Investment Co., Shanghai, China

Mincheol Kang*

Department of e-Business, School of Business, Ajou University, Suwon, South Korea

\section{Tegegne Tesfaye Haile}

College of Economics and Business Administration, The University of Suwon, South Korea

*Corresponding author: mckang@ajou.ac.kr

\begin{abstract}
Argument quality has become an important variable that promotes consumers' decision-making based on online reviews. It has two dimensions, perceived informativeness and perceived persuasiveness. Adopting dual-process theory, this study examines the effect of these two dimensions of argument quality on review adoption. Moreover, it investigates whether the relationships between argument quality and review adoption differ based on product type and review type. According to the multi-group analysis result, for attribute-centric reviews, search products have a better fit than experience products in the relationship of perceived informativeness and perceived persuasiveness, also for the relationship of perceived informativeness on review adoption, while experience products have a better fit than search products for the relationship of perceived persuasiveness on review adoption. For benefitcentric reviews, search products and experience products have no significant difference in any of the relationships. Furthermore, the result reveals that perceived persuasiveness mediates perceived informativeness and review adoption. The findings contribute to the understanding of the information adoption model with different review types and product types and help shopping websites develop better strategies for product recommendation reviews.
\end{abstract}

Keywords: Online shopping, Argument quality, Review adoption, Review type, Product type 


\section{Introduction}

Online shopping has been advanced by globalization, technology, and Internet connectivity (Pham, 2018). The fast growth and use of Internet technologies have provided a great opportunity for online users to share information with others. Consumers are using Web 2.0 tools like online discussion forums, consumer review sites, weblogs, social network sites, and so on to exchange opinions and valuable product information. The online reviews from online users are also known as electronic word-of-mouth (eWOM). Online users count on eWOM of a wide range of products or services to reduce product and purchase uncertainty (Gupta \& Harris, 2010; Saleem et al., 2017). eWOM contains product information from experienced peer consumers (Lee et al., 2009). This information contained from the eWOM could have a positive, negative, or neutral connotation (Jeong \& Koo, 2015). Positive online reviews significantly affect consumers' buying decisions. The $90 \%$ of the online review readers claim that their buying decisions are affected by positive online reviews, while negative online reviews affect $86 \%$ of the readers' buying decisions (Kaemingk, 2020).

One of the important informational factors that affect consumers' information adoption to decide is the quality of the argument provided (O'Keefe \& Jackson, 1995). A given argument might be a normatively good argument i.e., a high-quality argument or might be a normatively poor argument (a low-quality argument). Consumers would like to adopt online reviews that come from credible sources that are believed to have a high argument quality. Individual assessment of the information depends on the factors related to the attributes of the information itself and the source of the information. Argument quality (factor related to the information itself) and source credibility (factor related to the information sources) are identified as the two major determinants of consumers' information adoption in online communities (Watts \& Zhang, 2008). Since argument quality focuses on factors related to the information itself rather than its source, this study is limited to examining the factors related to the information itself than its source. Argument quality has two important dimensions i.e., perceived informativeness and perceived persuasiveness. These two dimensions are determinants of argument quality in online customer reviews.

Previous studies have confirmed that information factors, including argument quality and source credibility, predict the adoption of online reviews. Content, source, and receiver are important elements of message influence (Lou \& Yuan, 2019). Adapting this assertion, the current study presents product type (i.e., search products and experience products) as a message source, review type (i.e., attribute-centric reviews and benefit-centric reviews) as a message content (Maheswaran \& Sternthal, 1990), and the receiver who may carry individual perceptions to make a better decision through evaluating the quality of information. In the context of this study, the message refers to a review. This study aims to understand the relationship among the above three message elements. There have been few studies assessing the impact of the interaction effect of review type by product type on message processing.

Built upon the dual-process theory and the cognitive fit theory, this study, theoretically, has identified two dimensions of argument quality i.e., perceived informativeness and perceived persuasiveness in determining information adoption and investigating their influence on review adoption. From a practical perspective, this study has shown that the degree to which consumers adopt reviews depends on the type of review and type of product. 
This study has three important purposes (1) Investigating the relationship between the two dimensions of argument quality and review adoption, (2) Examining whether product type and review type have moderating effects on the relationships, and (3) Finally, observing the mediating role of perceived persuasiveness between perceived informativeness and review adoption.

\section{Literature Review}

Many of the largest online retailers, including Office Depot, Amazon, Home Depot and Macy's, encourage eWOM by allowing online reviews on the products they offer. Reading online reviews about products became customary before making purchasing decisions. Online reviews have a strong and credible influence on consumer behavior (Gupta \& Harris, 2010). Herd behavior plays an important role in consumers' information adoption in online review communities (Shen et al., 2014). Out of 91 percent of consumers who regularly or occasionally read online reviews, 84 percent of them trust online reviews as much as a personal recommendation (Marchant, 2014). People are more likely to purchase a product or service that has been recommended by friends or others (Xu et al., 2015). Many researchers stress the fact that marketers must realize the importance of online reviews and pay greater attention to manage online product reviews, especially, to get more positive consumer perceptions (Archak et al., 2011). Consumers want to be provided with an appropriate message and high-quality information about the product, and reviews are more likely seen by potential customers as trustworthy and credible (Kolomiiets et al., 2016). In the field of technologymediated environments, product type plays an important role in affecting consumer behavior. For different product type, consumers can have different perceptions although they read the same message. Thus, studies of online reviews need to consider the difference in product type (Weathers et al., 2007; Huang et al., 2009).

Petty and Cacioppo (1986) developed ELM (Elaboration Likelihood Model) of persuasion that suggests "important variations in the nature of persuasion are a function of the likelihood that receivers will engage in the elaboration of (that is, thinking about) information relevant to the persuasive issue" (O'Keefe, 2013). Several studies have used the ELM to investigate online reviews (Cheung \& Thadani, 2012). Depending on the degree of elaboration, two persuasion processes can be identified. The one based on a relatively high degree of thinking is called the central route to persuasion; whereas the one that occurs with relatively little thinking is termed as the peripheral route to persuasion (O'Keefe, 2013). The heuristic-systematic model, on the other hand, tries to explain how people receive and process persuasive messages. In heuristic-systematic, the systematic processing of information indicates that "People consider all relevant pieces of information, elaborate on these pieces of information, and form a judgment based on these elaborations" (Todorov et al., 2012).

In Cheung and Thadani (2012), where a systematic literature review of online review research is presented, some meaningful conclusions for market-level analysis and individual-level analysis were drawn. Compared with market-level research, individual-level appears getting more attention. Based on this construction, researchers propose several important dependent variables at individual-level, such as information adoption (Zhang, 1996; Cheung et al., 2009), brand attitude (Watts \& Zhang, 2008), and purchase intention (Park \& Kim, 2008; Park \& Lee, 2008). Further, they identify 
key independent variables such as argument quality (Chu \& Kamal, 2008), perceived informativeness (Park \& Lee, 2008), and source credibility (Zhang et al., 2014). This study found a dual-process theory, which includes elaboration likelihood model and heuristic systematic model, as an appropriate theory to investigate the influence of online product reviews at the individual level (Cheung \& Thadani, 2012).

Argument quality (systematic factor) and source credibility (heuristic factor) can affect consumer behavior in online communities with dual-process theory (Watts \& Zhang, 2008). Dual-process theory shows how consumers' persuasiveness perceptions are affected by different information type (Deutsch \& Gerard, 1955). This study considers argument quality derived from the dual-process theory as an independent variable that represents content-related perceptions. Argument quality is defined as a second-order factor with two first-order variables: perceived informativeness and perceived persuasiveness (Zhang et al., 2014).

\section{Dual-process Theory and Information Adoption}

Researchers have applied dual-process theory in studying human information processing. There are two models used for such research: the elaboration likelihood model (ELM) (Petty \& Cacioppo, 1986; Cheung \& Thadani, 2012) and the HeuristicSystematic model (HSM) (Chaiken, 1980). These models explain how information processing strategy could acquire favorite decision outcomes (Cheung et al., 2009; Gupta \& Harris, 2010). They provide similar conceptions in discussing information processing strategies with a central/systematic route and/or peripheral/heuristic route. Here, the central/systematic processing refers to the main argument content cues, while the peripheral/heuristic processing refers to environmental cues. Central/systematic route and/or peripheral/heuristic route work together to affect consumers whether to accept the message.

The dual-process theory has been used to explain how people are influenced before adopting ideas, or information (Sussman \& Siegal, 2003; Bhattacherjee \& Sanford, 2006). For example, Sussman and Siegal (2003) dual model is used in explaining how knowledge workers are affected to adopt the information that they received in emails; and also found that the assessment of information usefulness works as a mediator of the information adoption process. Information adoption is defined as the "extent to which consumers accept online reviews after purposefully assessing review validity and use those reviews for further decision making" (Shen et al., 2014). Information adoption considers the information internalization process, in which individuals accept information from external sources to enhance their knowledge or improve their decision-making (Shen et al., 2014). It is a process that people purposefully engage in when they use information (Cheung et al., 2008). The information provided by friends and the reference group influences consumers' decision making and this influence is called "informational social influence" (Rosen \& Olshavsky, 1987). Understanding the informational social influence is very important to investigate the impact of review adoption. Most users scan reviews before they make a purchase decision (Pitta \& Fowler, 2005). 


\section{Review Type: Attribute-centric vs. Benefit-centric}

Online consumer reviews play two roles as a source of social influence, which is an informant role and a recommender role (Park et al., 2007). As an informant role, online consumer reviews convey additional basic numbers representing attribute level information like attributes-centric information. While as a recommender role, reviews provide a positive or negative direction of product evaluation like benefits-centric information. These two types of online reviews can completely meet consumers' information needs to review adoption. Hence, suggesting review type as a message content variable (Maheswaran \& Sternthal, 1990), this study categorized reviews into two types: the attribute-centric type and the benefit-centric type.

Attribute-centric reviews represent reviewer's evaluations based on technical attribute descriptions such as objective data and numbers. An example of an attribute-centric review is, "The tablet has a metal frame and is just $5.6 \mathrm{~mm}$ thick and weighs only 392gm." By contrast, benefit-centric reviews represent a subjective judgment about each attribute to evaluate a product. An example of a benefit-centric review is, "It is light as a feather, very slim and ergonomic to use".

Attribute information has a better fit with experts than a novice, whereas benefit information has a better fit with a novice than experts since novice do not know the attributes of a product well (Maheswaran \& Sternthal, 1990). The effect of the type of reviews (i.e., attribute-centric and benefit-centric) on purchase intention is stronger for experts than for novices while the effect of the number of reviews on purchase intention is stronger for novices than experts (Park \& Kim, 2008).

\section{Product Type: Search Products vs. Experience Products}

Products are classified into search and experience products (Nelson, 1974). It is the most popular classification based on product features (Nelson, 1974; Klein, 1998; Huang et al., 2009). Search products are defined as those whose attribute information can be easily obtained before use or purchase, while experience products are those whose attribute information can be unknown until use or purchase of the product (Nelson, 1974). Search products can be easily described and have the most search features and attributes, such as product weight, size, and color ( $\mathrm{Xu}$ et al., 2015). Examples of search products are laptop, furniture, laser printer, etc. For experience products, searching for information is costlier and/or difficult than direct product experience. Examples of experience products are skin care products, perfumes, and so on. Online review effects are more or less dependent on product type (Park \& Lee, 2008). Klein (1998) argues that the effect of different review type presentations on consumer perceptions will not be the same with different product types and the relationship must be examined.

\section{Argument Quality}

Argument quality has been developed as an important variable in dual-process theory (Angst \& Agarwal, 2009; Stiff \& Mongeau, 2016). Argument quality refers to "the strength or plausibility of persuasive argumentation" (Cheung \& Thadani, 2012). The concept of argument quality is applied to explain that received information can persuade a person to perform a behavior (Cheung et al., 2009). Perceived informativeness and perceived persuasiveness are determinants of argument quality in 
online customer reviews (Zhang et al., 2014). Perceived informativeness is defined as "consumers' overall perceptions presenting the information quality-related characteristics of online reviews" (Ducoffe, 1996). High-quality information directly affects consumers' purchasing decisions (Park et al., 2007). Research in advertising has shown that informative advertisements have a greater effect on purchasing behavior (Ducoffe, 1996). Perceived persuasiveness is defined as "the strength of persuasiveness in online reviews" (Zhang, 1996). Persuasive perceptions have shown an impact on preferential consumer decision outcomes (Angst \& Agarwal, 2009). It is discovered that people more likely engage to use the information when it is more persuasive (Bhattacherjee \& Sanford, 2006). Hence, this study assumes that if a consumer considers the reviews, about his favorite product, have a high argument quality with high perceived informativeness and persuasiveness, then the consumer is more likely to adopt the information. This leads to the following hypotheses:

H1 Perceived informativeness positively affects review adoption.

H2 Perceived persuasiveness positively affects review adoption.

According to the dual-process theory, persuasiveness perceptions would be affected by informational influence, which is from the source and content about the reality (Deutsch \& Gerard, 1955). Perceived informativeness is related to the extent to which the message has provided necessary information that helps people to understand a new product. The more informative the information is the more persuasive perceptions consumers have increasing behavioral intention (Petty \& Cacioppo, 1984). Hence, this study assumes that persuasive perceptions are affected by perceived informativeness. Then, the following hypothesis is drawn:

H3 Perceived informativeness positively affects perceived persuasiveness.

\section{Cognitive Fit Theory}

The cognitive fit theory proposes that "the correspondence between task and information presentation format leads to better task performance for individual users" (Vessey \& Galletta, 1991). In particular, the theory argues that information processing and decision-making tasks would be enhanced when the task matches the information format (Vessey \& Galletta, 1991). Several studies showed the fit between the task and presentation format (Jiang \& Benbasat, 2007). Past studies reveal the impact of ITbased presentation formats fit with product types on consumer perceptions (Vessey et al., 2006; Huang et al., 2009). Park and Kim (2008) combined cognitive fit theory with the elaboration likelihood model (ELM) to investigate the effect of review type on purchase intention. Using the cognitive fit theory, they showed the type of reviews can be a key moderating factor to the relationship between consumer perspective and word of mouth. The effects of a type of review and the number of reviews are examined using the ELM.

Cognitive fit theory indicates that attribute-centric reviews have a better cognitive fit for getting information about search products by describing attribute level (Vessey \& Galletta, 1991; Vessey et al., 2006). As described earlier, attribute-centric reviews focus on objective data/attributes and search products have searchable attributes. On the other hand, benefit-centric reviews are based on subjective judgment and experience products are those whose attribute information is costly or difficult to be known until the products 
are consumed. Thus, attribute-centric reviews are likely to fit better with search products than experience products in information processing for review adoption. Similarly, benefit-centric reviews are likely to fit better with experience products than search products in information processing for review adoption. Thus, the following hypotheses are drawn:

H4 The interaction effect of review type and product type moderate the relationship between perceived informativeness and review adoption (for attribute-centric reviews, search products have a better fit than experience products).

H5 The interaction effect of review type and product type moderate the relationship between perceived persuasiveness and review adoption (for benefit-centric reviews, experience products have a better fit than search products).

The quality of online product reviews affects the acceptance of the review (Lee \& Shin, 2014). These effects also vary depending on the product type. Using a computer game as an experience good whose quality is difficult to assess before firsthand experience and vitamin as a search good whose quality can be easily evaluated, Lee and Shin (2014) have found that a high-quality review evaluated the product more positively. Search products and attribute-centric reviews are related to concrete information about product attributes. Concrete information has a better feeling of persuasiveness (Nisbett \& Ross, 1980). Thus, it is assumed that attribute-centric reviews are likely to fit better with search products than experience products in moderating the relationship between perceived informativeness and perceived persuasiveness. It is very difficult for consumers to judge the quality of experience products because experience products own more experience attributes, which need to be felt and seen (Nelson, 1974). The judgment of experience attributes involves considerable subjectivity and perceived risk. Arguments in benefit-centric reviews convey subjective interpretations of benefits about product attributes (Park \& Kim, 2008). Readers of such reviews need to evaluate the information described by other consumers in their way. Besides, both experience products and benefit-centric reviews require more cognitive efforts to process information about products or reviews as compared to their counterparts. Therefore, benefit-centric reviews are likely to fit better with experience products than search products in moderating the relationship between perceived informativeness and perceived persuasiveness. Accordingly, the following hypothesis is drawn:

H6 The interaction effect of review type and product type moderate the relationship between perceived informativeness and perceived persuasiveness (for attributecentric reviews, search products have a better fit than experience products).

Figure 1 below depicts the research model used in this study. This study examines the relationship between argument quality and review adoption and investigates whether there exists an interaction effect of review type and product type in moderating the relationship. Additionally, this study explores the relationship between perceived informativeness and perceived persuasiveness, which are the constructs of argument quality, and examines the interaction effect of review type and product type in moderating the relationship. 
Figure 1: Research Model

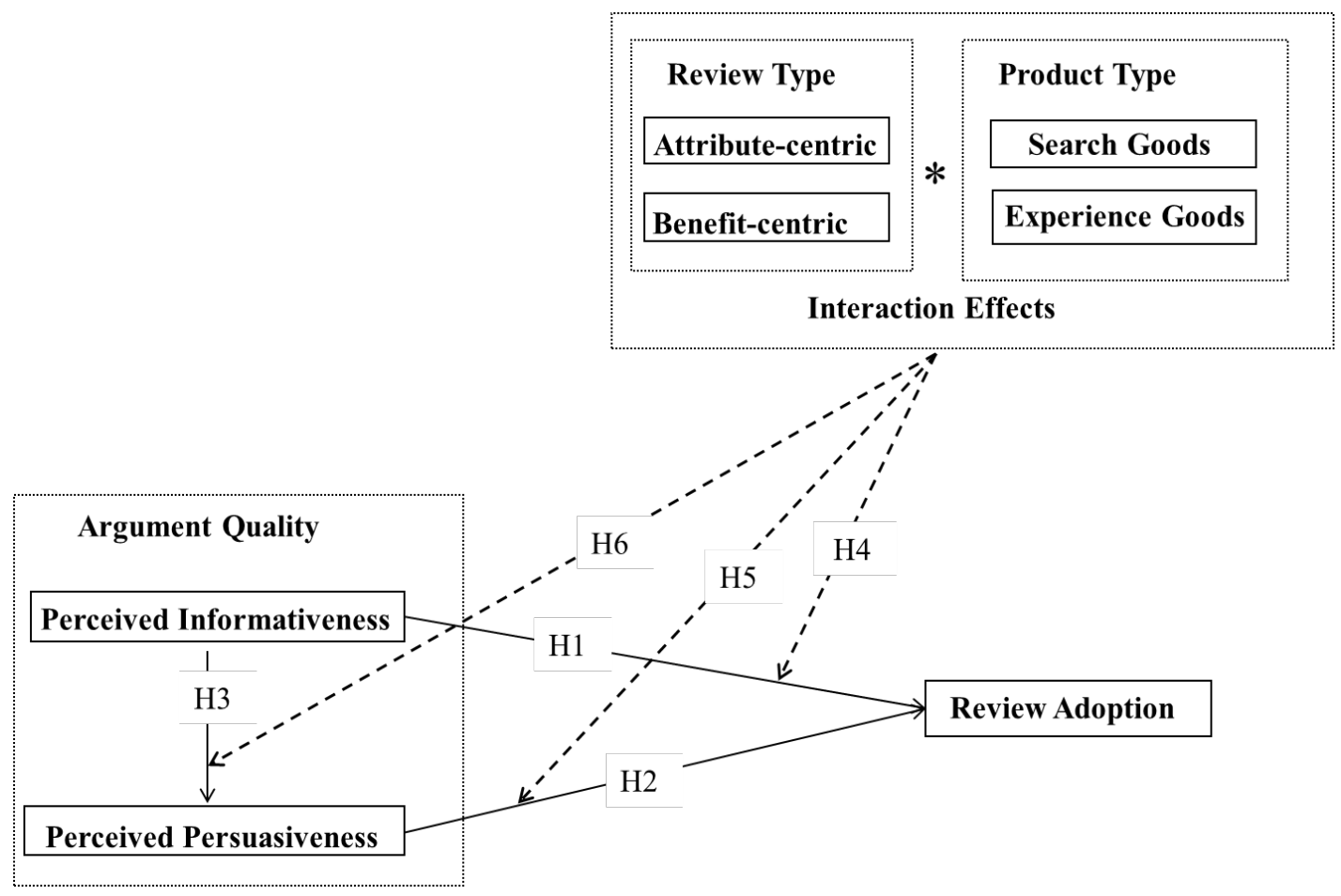

Methodology

\section{Selection of Products}

In keeping up with prior studies, this study compares search and experience products (Huang et al., 2009). To improve the validity of the data, two search products and two experience products are selected. Since tablets represent relatively standardized products whose features can be described easily, two tablets are chosen to represent search products. The information quality of tablets is relatively easy to identify. Then, beer is chosen (Weathers et al., 2007), which can be classified as an experience product. Beer is regarded as a kind of beverage that has many experience attributes and it is costly or difficult to judge its quality before purchase.

\section{Selection of Reviews and Pretest}

tmall.com (formerly known as taobao.com) is one of the most popular and largest online shopping sites in China. It is established in 2003 with about 500 million registered users in 2016. There are over 60 million regular visitors, and 48,000 items were sold per minute on average. "tablets" and "beers" reviews are selected and classified into attribute and benefit reviews based on the definitions and examples of attribute and benefit reviews from prior related studies (Maheswaran \& Sternthal, 1990; Park \& Lee, 2008). Visitors generally read 5 to 6 reviews of products, each with 3 to 4 lines, when surfing Internet shopping malls (Park \& Lee, 2008). Hence, 5 reviews are selected, each of which consists of 3 to 4 lines. This study focuses on favorable evaluations of a product because "positiveness of a review can provide a useful information for novices even when they cannot fully understand the reviews" (Park \& Kim, 2008). Further, positive reviews are selected and controlled with the same strength level. It is also 
confirmed that all compared reviews are of the same length and the same quantity. The difference between review type and product type is used as the way for evaluating a product.

Before undertaking the main experiment, a pretest is conducted to examine whether the classifications of review type were perceived as expected. 20 participants (who did not participate in the main experiment) were requested to classify the review type of attribute-centric and benefit-centric reviews. The results of the review type classification were as expected. Then, attribute-centric and benefit-centric reviews were prepared for the main experiment test.

Attribute-centric information and benefit-centric information were given for each of the four products. As a result, there were 8 sets of questionnaires - two sets of attributecentric reviews with search products (group 1), two sets of benefit-centric reviews with search products (group 2), two sets of attribute-centric reviews with experience products (group 3), and two sets of benefit-centric reviews with experience products (group 4). Eight different sets of online product reviews were prepared for each situation.

\section{Participants}

The small shopping forum owns a large population of shoppers who share their hobbies, topics of interest, and shopping mall events. The forum can be a highly effective channel to distribute a questionnaire to the shopping site users. Hence, the 8 sets survey questionnaire's URL is placed on the forum. Each participant randomly answered one of the eight questionnaire sets. To get more responses, an incentive of 1.0 RMB (about 0.15 US dollars) is provided to each participant.

\section{Experimental Procedures}

Participants read the first part of the survey, which is a statement about the study's purpose. The statements were the same for all sets. Then, participants were required to read product information including a product advertisement and some consumer product reviews. The advertisement has provided a picture and a brief description of the product. Consumer reviews were located under the product description. Each consumer read about one product with one type of review among the 8 review sets.

The survey with a multi-item was conducted where each variable was measured with a few items. There was a total of eleven measurement items provided to check the stimulus effects. Perceived informativeness was measured using three items and perceived persuasiveness using four items (Zhang et al., 2014). Review adoption was measured with four items (Cheung et al., 2009). All items were judged by a seven-point Likert scale, from strongly agree (1) to strongly disagree (7).

There were five questions administered to collect demographic information. The measurement items are presented in Table 1 below. 
Table 1: Variables and Measurements

\begin{tabular}{|c|c|c|}
\hline Variables & $\begin{array}{c}\text { Measurement items } \\
\text { Items on } 7 \text {-point ratings of agreement } \\
(1=\text { strongly disagree to } 7=\text { strongly agree) }\end{array}$ & References \\
\hline $\begin{array}{l}\text { Perceived } \\
\text { Informativeness }\end{array}$ & $\begin{array}{l}\text { PI1: These reviews provided relevant information about } \\
\text { the product } \\
\text { PI2: These reviews provided complete information } \\
\text { about the product } \\
\text { PI3: These reviews provided timely information about } \\
\text { the product }\end{array}$ & $\begin{array}{c}\text { (Zhang et al., } \\
\text { 2014) }\end{array}$ \\
\hline $\begin{array}{l}\text { Perceived } \\
\text { Persuasiveness }\end{array}$ & $\begin{array}{l}\text { PP1: The arguments of these reviews were convincing } \\
\text { PP2: The arguments of these reviews were persuasive } \\
\text { PP3: The arguments of these reviews were strong. } \\
\text { PP4: The arguments of these reviews were good }\end{array}$ & $\begin{array}{c}\text { (Zhang et al., } \\
\text { 2014) }\end{array}$ \\
\hline $\begin{array}{l}\text { Review } \\
\text { Adoption }\end{array}$ & $\begin{array}{l}\text { RA1: Information from review contributed to my } \\
\text { knowledge of discussed product } \\
\text { RA2: Review made it easier for me to make purchase } \\
\text { decision. (e.g., purchase or not purchase). } \\
\text { RA3: Review has enhanced my effectiveness in making } \\
\text { purchase decision. } \\
\text { RA4: Review motivated me to make purchase action. }\end{array}$ & $\begin{array}{l}\text { (Cheung et } \\
\text { al., 2009) }\end{array}$ \\
\hline
\end{tabular}

\section{Results}

In total, there were 337 participants. To enhance data validity, only those responders whose shopping frequency is at least once a month are selected. Besides, five respondents who failed the manipulation check questions are excluded. As a result, the study had a valid sample size of 319 . Since there are four different groups, for the attribute-centric reviews with search product, the usable sample is 79 ; for the benefitcentric reviews with search product, the usable sample is 76; for the attribute-centric reviews with experience product, the usable sample is 91 ; and for the benefit-centric reviews with experience product, the usable sample is 73 .

This study employed SmartPLS 3.0 multi-group Partial Least Squares (PLS) to analyze the research model. SmartPLS is a component-based structural equation modeling approach used to estimate cause-effect relationships between constructs (Henseler et al., 2016) and allows a relatively small sample size. And there are few restrictions with the data following normal distribution or not (Daft \& Lengel, 1986). The selected multigroup PLS path model was found in Festge and Schwaiger (2007) and in Homburg and Rudolph (2001). These two prior studies examined the relationship between customer satisfaction and customer loyalty in industrial markets.

\section{Measurement Model}

For the data analysis, first, reliability is confirmed by checking the composite reliability (CR) and Cronbach's alpha values. The criterion is that the value of each construct should be 0.7 or greater (Bagozzi \& Yi, 1988). Table 2 shows that all composite reliability (CR) and Cronbach's alpha values are over 0.7. Second, convergent and discriminant validity is checked for the full data set by conducting exploratory factor analysis (EFA) with SPSS and confirmatory factor analysis (CFA) with SmartPLS. One 
item from perceived informativeness and two items from perceived persuasiveness have failed to achieve validity. By deleting these items one by one, EFA and CFA is conducted again. All constructs have shown over the acceptable value (0.5) of average variance extracted (AVE) ranging from 0.820 to 0.914 (Fornell \& Larcker, 1981; Bagozzi \& Yi, 1988). Lastly, discriminant validity is checked where the square roots of the AVE (bold-font numbers in Table 3) for each construct is greater than the correlations among the constructs (Festge \& Schwaiger, 2007). As a result, data reliability and validity are achieved.

Table 2: Measurement Model Statistics for Complete Data

\begin{tabular}{|c|c|c|c|c|c|}
\hline Variable & Indicators & $\begin{array}{l}\text { Factor } \\
\text { Loadings }\end{array}$ & $\begin{array}{c}\text { Cronbach's } \\
\text { Alpha }\end{array}$ & $\begin{array}{c}\text { Composite } \\
\text { Reliability } \\
\text { (CR) }\end{array}$ & $\begin{array}{c}\text { Average } \\
\text { Variance } \\
\text { Extracted } \\
\text { (AVE) }\end{array}$ \\
\hline Perceived & PI2 & 0.905 & 0.788 & 0.904 & 0.820 \\
\hline Informativeness & PI3 & 0.911 & & & \\
\hline Perceived & PP1 & 0.954 & 0.907 & 0.955 & 0.914 \\
\hline Persuasiveness & PP2 & 0.958 & & & \\
\hline Review & RA1 & 0.891 & 0.929 & 0.948 & 0.825 \\
\hline \multirow{3}{*}{ Adoption } & RA2 & 0.919 & & & \\
\hline & RA3 & 0.913 & & & \\
\hline & RA4 & 0.900 & & & \\
\hline
\end{tabular}

Table 3: Latent Variable Correlations for Complete Data

\begin{tabular}{lccc}
\hline & $\begin{array}{c}\text { Review } \\
\text { Adoption }\end{array}$ & $\begin{array}{c}\text { Perceived } \\
\text { Informativeness }\end{array}$ & $\begin{array}{c}\text { Perceived } \\
\text { Persuasiveness }\end{array}$ \\
\hline Review Adoption & 0.906 & & \\
Perceived Informativeness & 0.560 & 0.908 & 0.956 \\
Perceived Persuasiveness & 0.704 & 0.718 & 0.96 \\
\hline
\end{tabular}

For the multi-group analysis, the first step in data analysis is to confirm the reliability and validity for each group as well. All analyses groups should show that all indicators exhibit factor loadings above 0.70 (Bagozzi \& Yi, 1988; Henseler, 2012), the constructs' average variance extracted (AVE) values should be greater than 0.50 (Fornell \& Larcker, 1981), and composite reliability values should be 0.80 or higher (Fornell \& Larcker, 1981).

There are two ways to assess the constructs' discriminant validity for each group. First, the indicators' cross-loading is checked. There were no higher indicator loads on an opposing construct (Hair et al., 2012). Then, each construct's AVE (Fornell \& Larcker, 1981 ) is verified, which should be greater than its squared correlation among the remaining constructs. Both analyses show that all constructs confirm discriminant validity. Overall, these results provide support for the reliability and convergent validity of the measures for each group and presented in Table 4 and Table 5 below. 
Table 4: Measurement Model Statistics for Each Group Data

\begin{tabular}{|c|c|c|c|c|c|}
\hline & Indicators & $\begin{array}{c}\text { Factor } \\
\text { Loadings }\end{array}$ & $\begin{array}{c}\text { Cronbach's } \\
\text { Alpha }\end{array}$ & $\begin{array}{l}\text { Composite } \\
\text { Reliability } \\
\text { (CR) }\end{array}$ & $\begin{array}{c}\text { Average } \\
\text { Variance } \\
\text { Extracted } \\
\text { (AVE) }\end{array}$ \\
\hline \multicolumn{6}{|c|}{ Group 1 Search product * Attribute-centric reviews } \\
\hline Perceived & PI2 & 0.871 & 0.729 & 0.880 & 0.786 \\
\hline Informativeness & PI3 & 0.902 & & & \\
\hline Perceived & PP1 & 0.908 & 0.810 & 0.913 & 0.840 \\
\hline Persuasiveness & PP2 & 0.925 & & & \\
\hline Review & RA1 & 0.872 & 0.917 & 0.942 & 0.801 \\
\hline \multirow[t]{3}{*}{ Adoption } & RA2 & 0.899 & & & \\
\hline & RA3 & 0.914 & & & \\
\hline & RA4 & 0.895 & & & \\
\hline \multicolumn{6}{|c|}{ Group 2 Search product * Benefit-centric reviews } \\
\hline Perceived & PI2 & 0.881 & 0.751 & 0.889 & 0.800 \\
\hline Informativeness & PI3 & 0.908 & & & \\
\hline Perceived & PP1 & 0.969 & 0.938 & 0.970 & 0.942 \\
\hline Persuasiveness & PP2 & 0.972 & & & \\
\hline Review & RA1 & 0.894 & 0.931 & 0.951 & 0.829 \\
\hline \multirow[t]{3}{*}{ Adoption } & RA2 & 0.930 & & & \\
\hline & RA3 & 0.907 & & & \\
\hline & RA4 & 0.912 & & & \\
\hline \multicolumn{6}{|c|}{ Group 3 Experience product * Attribute-centric reviews } \\
\hline Perceived & PI2 & 0.940 & 0.864 & 0.937 & 0.881 \\
\hline Informativeness & $\mathrm{PI} 3$ & 0.937 & & & \\
\hline Perceived & PP1 & 0.961 & 0.918 & 0.961 & 0.924 \\
\hline Persuasiveness & PP2 & 0.962 & & & \\
\hline Review & RA1 & 0.907 & 0.940 & 0.957 & 0.848 \\
\hline \multirow[t]{3}{*}{ Adoption } & RA2 & 0.937 & & & \\
\hline & RA3 & 0.937 & & & \\
\hline & RA4 & 0.903 & & & \\
\hline \multicolumn{6}{|c|}{ Group 4 Experience product * Benefit-centric reviews } \\
\hline Perceived & PI2 & 0.924 & 0.820 & 0.917 & 0.847 \\
\hline Informativeness & PI3 & 0.917 & & & \\
\hline Perceived & PP1 & 0.969 & 0.938 & 0.970 & 0.942 \\
\hline Persuasiveness & PP2 & 0.972 & & & \\
\hline Review & RA1 & 0.898 & 0.916 & 0.940 & 0.796 \\
\hline \multirow[t]{3}{*}{ Adoption } & RA2 & 0.899 & & & \\
\hline & RA3 & 0.889 & & & \\
\hline & RA4 & 0.884 & & & \\
\hline
\end{tabular}

Note: $\mathrm{N} 1=79, \mathrm{~N} 2=76, \mathrm{~N} 3=91, \mathrm{~N} 4=73$ 
Table 5: Latent Variable Correlations for Each Group

\begin{tabular}{|c|c|c|c|c|c|c|c|}
\hline \multicolumn{4}{|c|}{$\begin{array}{c}\text { Group1 } \\
\text { Search product * Attribute-centric reviews }\end{array}$} & \multicolumn{4}{|c|}{$\begin{array}{c}\text { Group2 } \\
\text { Search product * Benefit-centric reviews }\end{array}$} \\
\hline & RA & PI & $\mathrm{PP}$ & & RA & PI & PP \\
\hline RA & 0.895 & & & RA & 0.911 & & \\
\hline PI & 0.755 & 0.877 & & PI & 0.504 & 0.895 & \\
\hline PP & 0.763 & 0.860 & 0.917 & $\mathrm{PP}$ & 0.697 & 0.686 & 0.970 \\
\hline \multicolumn{4}{|c|}{$\begin{array}{c}\text { Group3 } \\
\text { oduct * Attribute-centric reviews }\end{array}$} & \multicolumn{4}{|c|}{$\begin{array}{c}\text { Group4 } \\
\text { Experience product * Attribute-centric reviews }\end{array}$} \\
\hline & RA & PI & PP & \multicolumn{4}{|c|}{$\begin{array}{lll}\text { RA } & \text { PI } & \text { PP }\end{array}$} \\
\hline RA & 0.921 & & & RA & 0.892 & & \\
\hline PI & 0.544 & 0.938 & & PI & 0.510 & 0.921 & \\
\hline PP & 0.789 & 0.656 & 0.961 & PP & 0.588 & 0.700 & 0.970 \\
\hline
\end{tabular}

Note: PI represents Perceived Informativeness; PP represents Perceived Persuasiveness; RA represents Review Adoption

\section{Structural Model}

A structural model analysis is conducted using SmartPLS with a bootstrapping resampling technique to test the hypotheses. Bootstrapping is a non-parametric resampling procedure that involves taking sampling frames from the data set repeatedly and estimating the indirect effect in each data set (Hayes, 2009). Path coefficients are examined by judging the t-value (significant paths have been shown with asterisks). Results of significance were based on the bootstrapping analysis with 50 bootstrap samples.

Perceived informativeness $(\beta=0.112, \quad \mathrm{t}=1.833, \quad \mathrm{p}$-value $<0.1), \quad$ and perceived persuasiveness $(\beta=0.623, \mathrm{t}=16.499, \mathrm{p}$-value $<0.001)$ were the key determinants of review adoption. The relationship between the two determinants is also examined. Perceived informativeness has a significant effect on perceived persuasiveness $(\beta=0.718, \mathrm{t}=11.116, \mathrm{p}$-value $<0.001)$. It is found that not every group supports the relationship between perceived informativeness and perceived persuasiveness. Only the search product with an attribute-centric review group supports a significant relationship between perceived informativeness and review adoption.

\section{Moderating Effect Analysis}

To analyze the moderating effect, a multi-group analysis is used by comparing the path coefficients difference of the four groups. If the compared two groups have a significant difference, it can be said that there is a moderating effect. Partial Least Squares multigroup analysis is a non-parametric significance test that builds on PLS-SEM bootstrapping results (Henseler, 2012) for analyzing group differences. Taking the significant level at 5 percent probability, it can be confirmed that there is a significant difference of group-specific path coefficients when the p-value is smaller than 0.05 or greater than 0.95 (Sarstedt et al., 2011).

For search products, attribute-centric reviews have a stronger effect than benefit-centric reviews. In other words, for attribute-centric reviews, search products have a better fit than experience products. For benefit-centric reviews, there is no significant difference between search products and experience products. 
For search products, attribute-centric reviews have a stronger effect than benefit-centric reviews. In other words, for attribute-centric reviews, search products have a better fit than experience products. Search products with attribute-centric reviews have a stronger effect than experience products with benefit-centric reviews. For benefitcentric reviews, there is no significant difference between search products and experience products.

For experience products, attribute-centric reviews have a stronger effect than benefitcentric reviews. In other words, for attribute-centric reviews, experience products have a better fit than search products. For benefit-centric reviews, there is no significant difference between search products and experience products.

\section{Mediating Effect Analysis}

To test the mediating effect, the three steps criteria by Baron and Kenny (1986) is adopted. For each effect in the path model, the effect size is calculated by using Fsquared (Cohen, 2013). The effect size F-squared is calculated as the increase in Rsquared relative to the proportion of variance of the endogenous variable that remains unexplained. According to Cohen (2013), when the F-squared value is between 0.02 and 0.15 , the effect is small; when the value is between 0.15 and 0.35 , the effect is medium, and when the value is greater than 0.35 , the effect is large. For the full data set, perceived persuasiveness showed a large partial mediating effect. For group 1 (i.e., Search Product*Attribute-centric Reviews), perceived persuasiveness showed a small partial mediating effect. For group 2 (i.e., Search Product*Benefit-centric Reviews), perceived persuasiveness showed a large fully mediating effect. For group 3 (i.e., Experience Product*Attribute-centric Reviews), perceived persuasiveness showed a large fully mediating effect. For group 4 (i.e., Experience Product*Benefit-centric Reviews), perceived persuasiveness showed a medium fully mediating effect (refer to Table 6). The result of this study is summarized in Table 7.

Table 6: Mediating Effect \& Cohen's Effect Size

\begin{tabular}{lcc}
\hline \multicolumn{1}{c}{ Data Set } & $\begin{array}{c}\text { Mediating } \\
\text { Effect }\end{array}$ & $\begin{array}{c}\text { Cohen's Effect Size } \\
\text { (F-squared) }\end{array}$ \\
\hline Complete Data & $\begin{array}{c}\text { Partial } \\
\text { mediating } \\
\text { Partial }\end{array}$ & 0.38 (Large) \\
Group 1. Search Products*Attribute-centric Reviews & $\begin{array}{c}\text { mediating } \\
\text { Fully }\end{array}$ & 0.12 (Small) \\
Group 2. Search Products*Benefit-centric Reviews & $\begin{array}{c}\text { mediating } \\
\text { Fully }\end{array}$ & 0.85 (Large) \\
$\begin{array}{l}\text { Group 3. Experience Products*Attribute-centric } \\
\begin{array}{l}\text { Reviews } \\
\text { Group 4. Experience Products *Benefit-centric }\end{array}\end{array}$ & $\begin{array}{c}\text { Fully } \\
\text { mediating }\end{array}$ & 0.16 (Medium) \\
\hline
\end{tabular}

F-squared $=$ effect size: Small $(\mathrm{F}$-squared $=0.02) ;$ Medium $($ F-squared $=0.15) ;$ Large $(F$-squared $=0.35)$ 
Table 7: Research Results

\begin{tabular}{|c|c|}
\hline Hypothesis & Result \\
\hline Complete Data: H1: PI $\rightarrow$ RA & Supported \\
\hline Group 1. Search Products*Attribute-centric Reviews - H1: PI $\rightarrow$ RA & Supported \\
\hline Group 2. Search Products*Benefit-centric Reviews - H1: PI $\rightarrow$ RA & Not Supported \\
\hline Group 3. Experience Products*Attribute-centric Reviews - H1: PI $\rightarrow$ RA & Not Supported \\
\hline Group 4. Experience Products *Benefit-centric Reviews - H1: PI $\rightarrow$ RA & Not Supported \\
\hline Complete Data: H2: PP $\rightarrow$ RA & Supported \\
\hline Group 1. Search Products*Attribute-centric Reviews - H2: PP $\rightarrow$ RA & Supported \\
\hline Group 2. Search Products*Benefit-centric Reviews - H2: $\mathrm{PP} \rightarrow \mathrm{RA}$ & Supported \\
\hline Group 3. Experience Products*Attribute-centric Reviews - H2: PP $\rightarrow$ RA & Supported \\
\hline Group 4. Experience Products *Benefit-centric Reviews - H2: PP $\rightarrow$ RA & Supported \\
\hline Complete Data: H3: PI $\rightarrow$ PP & Supported \\
\hline Group 1. Search Products*Attribute-centric Reviews - H3: PI $\rightarrow$ PP & Supported \\
\hline Group 2. Search Products*Benefit-centric Reviews - H3: PI $\rightarrow$ PP & Supported \\
\hline Group 3. Experience Products*Attribute-centric Reviews - H3: PI $\rightarrow \mathrm{PP}$ & Supported \\
\hline Group 4. Experience Products *Benefit-centric Reviews - H3: PI $\rightarrow$ PP & Supported \\
\hline Complete Data: H4: Mediating Effect of PP on PI $\rightarrow$ RA & Supported \\
\hline $\begin{array}{c}\text { Group 1. Search Products*Attribute-centric Reviews } \\
\text { H4: Mediating Effect of PP on PI } \rightarrow \text { RA }\end{array}$ & Supported \\
\hline $\begin{array}{c}\text { Group 2. Search Products*Benefit-centric Reviews } \\
\text { H4: Mediating Effect of PP on PI } \rightarrow \text { RA }\end{array}$ & Supported \\
\hline $\begin{array}{c}\text { Group 3. Experience Products*Attribute-centric Reviews } \\
\text { H4: Mediating Effect of PP on PI } \rightarrow \text { RA }\end{array}$ & Supported \\
\hline $\begin{array}{c}\text { Group 4. Experience Products *Benefit-centric Reviews } \\
\text { H4: Mediating Effect of PP on PI } \rightarrow \text { RA }\end{array}$ & Supported \\
\hline Complete Data: H4: Moderating Effect of RT*PT on PI $\rightarrow$ RA & Supported \\
\hline Complete Data: H5: Moderating Effect of RT*PT on PP $\rightarrow R A$ & Not Supported \\
\hline Complete Data: H6: Moderating Effect of RT*PT on PI $\rightarrow$ PP & Supported \\
\hline
\end{tabular}

\section{Discussion}

This study aims to achieve an understanding of the interaction effects of review type by product type on argument quality and online reviews adoption. For the full data set, the results show that there is a positive relationship between perceived informativeness (i.e., at a $\mathrm{p}<0.001$ significance level), perceived persuasiveness (i.e., at a $\mathrm{p}<0.10$ significance level) and review adoption. Perceived informativeness of the review provided for a product has an impact on consumers' behavior. If the consumer is wellinformed about the product by the review given, then there is a high probability that the consumer will adopt the review. Studies show that perceived informativeness has a positive and significant effect on purchasing intention (Park \& Lee, 2008). From this, 
one could infer that the increase in purchasing intention is because the consumers have adopted the reviews. Perceived persuasiveness has also been shown to positively influence review adoption. Consumers' attitudes or behavior can be shaped by the persuasiveness of the system (Oinas-Kukkonen \& Harjumaa, 2009). There is a high chance that the consumer will adopt a review if he/she perceives the review as persuasive. The informational role of a review also has a positive impact on its persuasiveness. In general, consumers get informative perceptions first when they read the content of online reviews, then get persuasive perceptions. Going from informativeness perceptions to persuasiveness perceptions is a cognitive process.

Different review types with the right product type can provide helpful information to customers. Informative reviews are important and can give the necessary information that assists consumers to mitigate uncertainty and improve the probability of review adoption and purchase decision. In other words, if the reviews are more persuasive consumers are more likely to follow the recommendations. Examining hypothesis 1, hypothesis 2, and hypothesis 3 for each group, it is found that only group 1 (i.e., search product with attribute-centric reviews) shows a significant relationship between perceived informativeness and review adoption. This could be because attribute-centric reviews give more important information for products with search characteristics. The remaining three groups show that there is no significant relationship between perceived informativeness and review adoption. Based on these structures, it can be inferred that there is a mediating effect of perceived persuasiveness between informativeness and review adoption for the complete data and each group data. The results of the analysis supported the hypotheses. Specifically, it is found that perceived persuasiveness partially mediates the relationship between informativeness and review adoption for complete data. Meanwhile, only search product by attribute-centric review group (group1) shows that perceived persuasiveness is a partial mediating variable between informativeness and review adoption. The other three groups show that perceived persuasiveness is a fully mediating variable between informativeness and review adoption.

This study has several limitations and also opportunities for future study. First, the data for the four groups are collected adopting a single review type with one single product type as the research context. Hence, the generalizability of the findings for the different review types together may be limited. Future studies should consider extending this study's findings by combining the context of online review types (i.e., attribute-centric review and benefit review together).

Second, the data for this study is collected from one single online shopping forum website (i.e., tmall.com). Since perceptions on different online shopping forums might be different, the findings may be limited to be generalized to other forums. Future researchers can do a comparative analysis of different online shopping sites and extend this study's findings. In different online platforms, control variables such as cultural backgrounds, product types and personality could be considered. Previous research points out that there are different effects in different consumer opinion platforms (Li \& Hitt, 2008; Park \& Lee, 2009; Cheung \& Thadani, 2012). These opinion platforms could be weblogs, review websites, retail websites, and social networking sites, and so on. For instance, Li and Hitt (2008) have investigated the moderating effect of positive eWOM on consumers' belief, attitude, and behavioral intention to shop online in a real UK watch selling website (www.easywatch.com). Further, the influence of online 
reviews may vary with other review formats like text-based reviews and video-based reviews (Xu et al., 2015) or other product types like quality products and preference products (Lee and Lee, 2009).

Third, this study has only focused on positive reviews since survey-based approach is viable when most reviews approaches are neutral and extremely positive (Hu et al., 2009). Prior studies have proved that negative reviews have stronger effects than positive reviews on consumer perceptions. Consumers are more likely to believe negative reviews than positive reviews (Park \& Lee, 2008). Thus, it will be interesting to explore which factor has a stronger effect on reviews adoption than positive reviews.

Finally, the framework used in this study has only focused on the impact of argument quality derived from dual-process theory on review adoption. Other variables like information quality, information credibility, source credibility, and others in dualprocess that might influence consumers' decision making are not explained. Future studies should look into other factors that might be included in dual-process or other applicable theories.

\section{Implications}

The findings of this study have important implications for theory and research. This study enriches the understanding of the effect of argument quality on review adoption. Prior studies show that argument quality and source credibility are important determinants of information adoption in online communities (Watts \& Zhang, 2008). Applying the information adoption model into consumer behavior, this study has extended prior studies by identifying two dimensions of argument quality, i.e., perceived informativeness and perceived persuasiveness (Zhang et al., 2014), which have different systematic processing in determining information adoption and investigating their influence on review adoption.

\section{Implications for Asian Business}

This study provides some useful recommendations for marketers and brands in Asian that sell their products online. For example, because online shoppers rely on online reviews to make purchasing decisions, marketers have to place significant attention to the argument quality. They should also be aware that the relationship between argument quality and review adoption could differ based on the product type and review type. Marketers need to provide a different form of product information for different product types.

This study has exposed that the degree to which consumers adopt reviews is dependent on the type of review and type of product. Designers of online reviews and marketers should carefully consider the kind of review and the characteristics of the product to provide a high-quality online review (Maheswaran \& Sternthal, 1990; Park \& Lee, 2009). Also, it is found information timeliness and information completion are the most important factors influencing perceived informativeness. Hence, marketers and vendors should make sure that timely and complete information is provided to grab consumer attention and enhance persuasiveness. Furthermore, marketers should keep in mind that 
for experience products attribute-centric reviews help more to persuade consumers to adopt the reviews and enhance their purchase intention.

The results of this study provide strong empirical support that consumers' perceptions of argument quality and information adoption vary by review type and product type. If consumers receive attribute-centric reviews about search products, then they will perceive more informativeness and like to adopt the review. If consumers receive attribute-centric reviews about experience products, then they will perceive it as more persuasive. Moreover, there is no significant difference between search products and experience products with benefit reviews.

The empirical results support the idea that the interaction effects of review type by product type moderate the relationship between perceived informativeness and review adoption. For attribute-centric reviews, search products have a better fit than experience products. And there is a significant difference between perceived informativeness and perceived persuasiveness. This could be because attribute-centric reviews are enough to know details about the product. It doesn't require the consumer to have a direct experience with the product. The interaction effect also moderates the relationship between perceived persuasiveness and review adoption. Since benefit reviews require consumers to explain and imagine the experience attributes, they need more cognitive effort; while attribute-centric reviews reduce uncertainties and decrease cognitive efforts because it shows other consumers' contents clearly and unambiguously. The findings supported the hypothesis that for attribute-centric reviews experience products have a better fit than search products; while for benefit-centric reviews, there are no significant differences between search products and experience products (refer to Table 7). Furthermore, for benefit-centric reviews, there is no significant difference between search products and experience products for any relationship. This might be related to the fact that in benefit-centric reviews, supporting arguments convey subjective interpretations. Moreover, benefit-centric reviews are a better fit for consumers with low expertise (Park \& Kim, 2008).

In addition to showing that perceived persuasiveness has a greater effect on review adoption than perceived informativeness, the findings reveal that perceived persuasiveness mediates the effect of perceived informativeness on review adoption. Furthermore, this study has examined the interaction effect of review type using product type as a moderator. As the findings suggest, the adoption of reviews could be determined by the type of review or type of product under consideration.

\section{Acknowledgement}

This work was supported by the Ajou University research fund.

\section{References}

Angst, C.M. and Agarwal, R. (2009) 'Adoption of electronic health records in the presence of privacy concerns: The elaboration likelihood model and individual persuasion', MIS quarterly, 33(2), pp. 339-370.

Archak, N., Ghose, A. and Ipeirotis, P.G. (2011) 'Deriving the pricing power of product 
features by mining consumer reviews', Management science, 57(8), pp. 1485-1509.

Bagozzi, R.P. and Yi, Y. (1988) 'On the evaluation of structural equation models', Journal of the academy of marketing science, 16(1), pp. 74-94.

Baron, R.M. and Kenny, D.A. (1986) 'The moderator-mediator variable distinction in social psychological research: Conceptual, strategic, and statistical considerations.', Journal of personality and social psychology, 51(6), p. 1173.

Bhattacherjee, A. and Sanford, C. (2006) 'Influence processes for information technology acceptance: An elaboration likelihood model', MIS quarterly, pp. 805-825.

Chaiken, S. (1980) 'Heuristic versus systematic information processing and the use of source versus message cues in persuasion.', Journal of personality and social psychology, 39(5), p. 752.

Cheung, C.M. K., Lee, M.K.O. and Rabjohn, N. (2008) 'The impact of electronic word-ofmouth: The adoption of online opinions in online customer communities', Internet Research: Electronic Networking Applications and Policy, 18(3), pp. 229-247.

Cheung, C.M.K. and Thadani, D.R. (2012) 'The impact of electronic word-of-mouth communication: A literature analysis and integrative model', Decision support systems, 54(1), pp. 461-470.

Cheung, M.Y., Luo, C., Sia, C.L. and Chen, H. (2009) 'Credibility of electronic word-of-mouth: Informational and normative determinants of on-line consumer recommendations', International journal of electronic commerce, 13(4), pp. 9-38.

Chu, S-C. and Kamal, S. (2008) 'The effect of perceived blogger credibility and argument quality on message elaboration and brand attitudes: An exploratory study', Journal of interactive Advertising, 8(2), pp. 26-37.

Cohen, J. (2013) Statistical power analysis for the behavioral sciences. Academic press.

Daft, R.L. and Lengel, R.H. (1986) 'Organizational information requirements, media richness and structural design', Management science, 32(5), pp. 554-571.

Deutsch, M. and Gerard, H.B. (1955) 'A study of normative and informational social influences upon individual judgment.', The journal of abnormal and social psychology, 51(3), p. 629.

Kaemingk, D. (2020) Online Review Statistics to Know in 2021 // Qualtrics. Available at: https://www.qualtrics.com/blog/online-review-stats/ (Accessed: 9 December 2020).

Ducoffe, R.H. (1996) 'Advertising value and advertising on the web-Blog@ management', Journal of advertising research, 36(5), pp. 21-32.

Festge, F. and Schwaiger, M. (2007) 'The drivers of customer satisfaction with industrial goods: An international study', Advances in international marketing, 18, pp. 179-207.

Fornell, C. and Larcker, D.F. (1981) 'Evaluating structural equation models with unobservable variables and measurement error', Journal of marketing research, 18(1), pp. 39-50.

Gupta, P. and Harris, J. (2010) 'How e-WOM recommendations influence product consideration and quality of choice: A motivation to process information perspective', Journal of Business Research, 63(9-10), pp. 1041-1049.

Hair, J.F., Sarstedt, M., Ringle, C.M. and Mena, J.A. (2012) 'An assessment of the use of partial least squares structural equation modeling in marketing research', Journal of the academy of marketing science, 40(3), pp. 414-433.

Hayes, A.F. (2009) 'Beyond Baron and Kenny: Statistical mediation analysis in the new millennium', Communication Monographs, 76(4), pp. 408-420. doi: 10.1080/03637750903310360.

Henseler, J. (2012) 'PLS-MGA: A non-parametric approach to partial least squares-based multi-group analysis', in Challenges at the interface of data analysis, computer science, and optimization. Springer, pp. 495-501.

Henseler, J., Ringle, C.M. and Sarstedt, M. (2016) 'Testing measurement invariance of composites using partial least squares', International Marketing Review, 33(3), pp. 405-431. doi: 10.1108/IMR-09-2014-0304.

Homburg, C. and Rudolph, B. (2001) 'Customer satisfaction in industrial markets: dimensional and multiple role issues', Journal of Business research, 52(1), pp. 15-33.

$\mathrm{Hu}$, N., Zhang, J. and Pavlou, P.A. (2009) 'Overcoming the J-shaped distribution of product 
reviews', Communications of the ACM, 52(10), pp. 144-147.

Huang, P., Lurie, N.H. and Mitra, S. (2009) 'Searching for experience on the web: an empirical examination of consumer behavior for search and experience goods', Journal of marketing, 73(2), pp. 55-69.

Jeong, H-J. and Koo, D-M. (2015) 'Combined effects of valence and attributes of e-WOM on consumer judgment for message and product', Internet Research.

Jiang, Z. and Benbasat, I. (2007) 'Research note-investigating the influence of the functional mechanisms of online product presentations', Information Systems Research, 18(4), pp. 454-470.

Klein, L.R. (1998) 'Evaluating the potential of interactive media through a new lens: Search versus experience goods', Journal of business research, 41(3), pp. 195-203.

Kolomiiets, A., Dens, N. and De Pelsmacker, P. (2016) 'The wrap effect in online review sets revisited: How perceived usefulness mediates the effect on intention formation', Journal of Electronic Commerce Research, 17(4), pp. 280-288.

Lee, E.J. and Shin, S.Y. (2014) 'When do consumers buy online product reviews? Effects of review quality, product type, and reviewer's photo', Computers in Human Behavior, 31(1), pp. 356-366. doi: 10.1016/j.chb.2013.10.050.

Lee, J. and Lee, J-N. (2009) 'Understanding the product information inference process in electronic word-of-mouth: An objectivity-subjectivity dichotomy perspective', Information \& Management, 46(5), pp. 302-311.

Lee, M., Rodgers, S. and Kim, M. (2009) 'Effects of valence and extremity of eWOM on attitude toward the brand and website', Journal of Current Issues \& Research in Advertising, 31(2), pp. 1-11.

Li, X. and Hitt, L.M. (2008) 'Self-selection and information role of online product reviews', Information Systems Research, 19(4), pp. 456-474.

Lou, C. and Yuan, S. (2019) 'Influencer Marketing: How Message Value and Credibility Affect Consumer Trust of Branded Content on Social Media', Journal of Interactive Advertising, 19(1), pp. 58-73. doi: 10.1080/15252019.2018.1533501.

Maheswaran, D. and Sternthal, B. (1990) 'The effects of knowledge, motivation, and type of message on ad processing and product judgments', Journal of consumer Research, 17(1), pp. 66-73.

Marchant, R. (2014) Local Consumer Review Survey 2014, BrightLocal. Available at: https://www.brightlocal.com/research/local-consumer-review-survey-2014/ (Accessed: 9 December 2020).

Nelson, P. (1974) 'Advertising as information', Journal of political economy, 82(4), pp. 729754.

Nisbett, R.E. and Ross, L. (1980) Human inference: Strategies and shortcomings of social judgment.

O'Keefe, D.J. (2013) 'Elaboration Likelihood Model', in The International Encyclopedia of Communication. Chichester, UK: John Wiley \& Sons, Ltd. doi: 10.1002/9781405186407.wbiece011.pub2.

O'Keefe, D.J. and Jackson, S. (1995) 'Argument quality and persuasive effects: A review of current approaches', in Argumentation and values: Proceedings of the ninth Alta conference on argumentation. Speech Communication Association Annandale, pp. 8892.

Oinas-Kukkonen, H. and Harjumaa, M. (2009) 'Persuasive systems design: Key issues, process model, and system features', Communications of the Association for Information Systems, 24(1), p. 28.

Park, C. and Lee, T.M. (2009) 'Information direction, website reputation and eWOM effect: A moderating role of product type', Journal of Business research, 62(1), pp. 61-67.

Park, D-H. and Kim, S. (2008) 'The effects of consumer knowledge on message processing of electronic word-of-mouth via online consumer reviews', Electronic commerce research and applications, 7(4), pp. 399-410.

Park, D-H. and Lee, J. (2008) 'eWOM overload and its effect on consumer behavioral intention depending on consumer involvement', Electronic Commerce Research and 
Applications, 7(4), pp. 386-398.

Park, D-H., Lee, J. and Han, I. (2007) 'The effect of on-line consumer reviews on consumer purchasing intention: The moderating role of involvement', International journal of electronic commerce, 11(4), pp. 125-148.

Petty, R.E. and Cacioppo, J.T. (1984) 'The effects of involvement on responses to argument quantity and quality: Central and peripheral routes to persuasion.', Journal of personality and social psychology, 46(1), p. 69.

Petty, R.E. and Cacioppo, J.T. (1986) 'The elaboration likelihood model of persuasion', in Communication and persuasion. Springer, pp. 1-24.

Pham, T.L. (2018) 'An empirical investigation of consumer perceptions of online shopping in an emerging economy', Asia Pacific Journal of Marketing and Logistics.

Pitta, D.A. and Fowler, D. (2005) 'Online consumer communities and their value to new product developers', Journal of Product \& Brand Management.

Rosen, D.L. and Olshavsky, R.W. (1987) 'The dual role of informational social influence: Implications for marketing management', Journal of Business Research, 15(2), pp. $123-144$.

Saleem, M.A., Zahra, S. and Yaseen, A. (2017) 'Impact of service quality and trust on repurchase intentions-the case of Pakistan airline industry', Asia Pacific Journal of Marketing and Logistics.

Sarstedt, M., Henseler, J. and Ringle, C.M. (2011) 'Multigroup analysis in partial least squares (PLS) path modeling: Alternative methods and empirical results', in Measurement and research methods in international marketing. Emerald Group Publishing Limited.

Shen, X-L., Zhang, K.Z.K. and Zhao, S.J. (2014) 'Understanding information adoption in online review communities: the role of herd factors', in 2014 47th Hawaii International Conference on System Sciences. IEEE, pp. 604-613.

Stiff, J.B. and Mongeau, P.A. (2016) Persuasive communication. Guilford Publications.

Sussman, S.W. and Siegal, W.S. (2003) 'Informational influence in organizations: An integrated approach to knowledge adoption', Information systems research, 14(1), pp. $47-65$.

Todorov, A., Chaiken, S. and Henderson, M.D. (2012) 'The Heuristic-Systematic Model of Social Information Processing', in The Persuasion Handbook: Developments in Theory and Practice, pp. 195-212. doi: 10.4135/9781412976046.n11.

Vessey, I. and Galletta, D. (1991) 'Cognitive fit: An empirical study of information acquisition', Information systems research, 2(1), pp. 63-84.

Vessey, I., Zhang, P. and Galletta, D. (2006) 'The theory of cognitive fit', Human-computer interaction and management information systems: Foundations, 5, pp. 141-183.

Watts, S.A. and Zhang, W. (2008) 'Capitalizing on content: Information adoption in two online communities', Journal of the association for information systems, 9(2), p. 3.

Weathers, D., Sharma, S. and Wood, S.L. (2007) 'Effects of online communication practices on consumer perceptions of performance uncertainty for search and experience goods', Journal of retailing, 83(4), pp. 393-401.

$\mathrm{Xu}, \mathrm{P} ., \mathrm{C}$ Ch, L. and Santhanam, R. (2015) 'Will video be the next generation of e-commerce product reviews? Presentation format and the role of product type', Decision Support Systems, 73, pp. 85-96.

Zhang, K.Z.K., Zhao, S.J., Cheung, C.M.K. and Lee, M.K.O. (2014) 'Examining the influence of online reviews on consumers' decision-making: A heuristic-systematic model', Decision Support Systems, 67, pp. 78-89.

Zhang, Y. (1996) 'Responses to humorous advertising: The moderating effect of need for cognition', Journal of advertising, 25(1), pp. 15-32. 